\title{
A perda da espacialidade no romance $A$ morte e o meteoro de Joca Reiners Terron
}

\author{
Andre Rezende Benatti (UFMS)* \\ https://orcid.org/0000-0001-8909-8347
}

Rute Pereira da Silva (UFMS)**
https://orcid.org/0000-0002-3553-4139

Resumo:

Este artigo tem por objetivo analisar questões acerca da perda da espacialidade na construção do enredo na obra A morte e o meteoro, de Joca Reiners Terron, escrito em 2019. Narrativa em quatro capítulos intitulados: Grande Mal; Apagar o sobrenome; Não morrer mais e Cosmogonia. No romance é contada a história, que se passa em um futuro não muito distante do atual, em uma Amazônia destruída. E que nos é contado por um narrador, cujo nome não é apontado na obra. No decorrer da trama, os espaços e as ambientações são construídos de forma a levar o leitor a perceber que o extermínio total da tribo indígena dos kaajapukugi se deu por variados acontecimentos que se interligam. Para tal leitura tomamos por base conceitos críticos e literários, como aporte estudos referentes ao espaço e a ambientação, tais como Lima Barreto e o espaço romanesco, de Osman Lins, Espaço e romance, de Antônio Dimas, entre outros.

Palavras-chave: Espaço; Ambientação; Joca Reiners Terron.

\section{Abstract:}

\section{The loss of spatiality in the novel A morte e o meteoro of Joca Reiners Terron}

This article aims to analyze questions about the loss of spatiality in the construction of the plot in the work A morte eo meteoro, by Joca Reiners Terron, written in 2019. Narrative in four chapters entitled: Grande Evil; Delete the

* Doutor em Letras Neolatinas: estudos literários neolatinos pela Universidade Federal do Rio de Janeiro (2018). Atualmente é professor adjunto - nível IV da Universidade Estadual de Mato Grosso do Sul; Professor do quadro permanente do Programa de Pós-graduação em Estudos de Linguagens da Universidade Federal de Mato Grosso do Sul; Professor permanente do Programa de Pós-graduação em Letras da Universidade Estadual de Mato Grosso do Sul. Editor-chefe da REVELL - Revista de Estudos Literários da UEMS. Coordenador do GT Relações Literárias Interamericanas da Associação Nacional de Pós-Graduação e Pesquisa em Letras e Linguística - ANPOLL, biênio 2021-2023. Membro Suplente do Conselho Deliberativo da Associação Nacional de Pós-Graduação e Pesquisa em Letras e Linguística - ANPOLL, área de Estudos Literários - 2021-2023. Lattes: http://lattes.cnpq.br/8908183939079152. E-mail: andre_benatti29@hotmail.com

** Mestranda em Estudos de Linguagens na Universidade Federal de Mato Grosso do Sul. Graduada em Letras pela Universidade Federal do Ceará. Lattes: http://lattes.cnpq.br/0288673335091638. E-mail: ruteeloisio@gmail.com 
last name; No more dying and Cosmogony, in it the story is told, which takes place in a future not too distant from the present, in a destroyed Amazon. And that is told to us by a narrator, whose name is not mentioned in the work. During the plot, the spaces and settings are constructed in such a way as to make the reader realize that the total extermination of the indigenous tribe of the Kaajapukugi took place through various interconnected events. For this reading, we take as a basis, in addition to critical and literary concepts related to literary aesthetics, studies referring to space and setting will also serve us, such as Lima Barreto and the novel space, by Osman Lins, Space and novel, by Antônio Dimas, among others.

Keywords: Space; Atmosphere; Joca Reiners Terron.

Em Aspectos do Romance (2004), E.M. Forster nos afirma que a estória narra a vida no tempo - tempo este que está localizado em determinado espaço - e conta fatos da "vida" de pessoas, conforme as nomenclaturas adotadas por Forster. As pessoas são entendidas pelo crítico como massa verbal que é parte do autor. Tais pessoas das narrativas nunca serão pessoas reais, pois a função do romancista, assim como afirma Foster (2004), é escrever o que estaria oculto na vida de determinada personagem, tornando -a literária, mesmo que tenha sido histórica, pois de personagens empíricas não se pode saber tudo e é isto o que difere pessoas reais de pessoas literárias.

Forster (2004) ainda nos fala sobre compreendemos como "interdependência" estrutural da narrativa, ou seja, as microestruturas narrativas dependem uma das outras para se construírem no romance, por exemplo. Contudo, apesar de concordarmos com a proposição de Forster (2004) e sabermos da importância igualitária de todas as microestruturas narrativas, nos deteremos mais na categoria do espaço. 0 espaço e o tempo são, juntamente com os demais elementos da narrativa, um fio condutor do enredo, que se entrelaçam, refletindo vários outros.

Em Lima Barreto e o Espaço Romanesco (1976, p. 63-64), Osman Lins, aponta esse ca- minho quando diz que "não só espaço e tempo, quando nos debruçamos sobre a narrativa, são indissociáveis. A narrativa é um objeto compacto e inextrincável, todos os seus fios se enlaçam entre si e cada um reflete inúmeros outros".

Em uma narrativa, o espaço pode assumir variadas significações, objetivos e funções. Em algumas obras o espaço pode assumir papel "rarefeito ou impreciso" (LINS, p. 65), porém em outras o espaço "atua com seu peso" (LINS, p. 65). Na narrativa $A$ morte e o meteoro o espaço assume papel de grande relevância, desde seu início:

Tendo saído da Amazônia, de um lugar mais quente que o inferno e onde as chuvas equatoriais já não caíam tão caudalosas quanto no passado, dificilmente se adaptariam aos rigores negativos do clima canadense. Assim terminaram em Oaxaca.

Se a zona árida da planície daqui não servia para eles, nada mais no mundo se parecia com a selva amazônica ou com aquilo que restava dela, algumas dezenas de hectares de árvores agonizantes em vias de serem calcinadas pelo sol. [...] viviam numa paisagem desertificada sem estarem preparados. (TERRON, 2019, p. 11).

Construída a partir de um conto, que se transformou no primeiro capítulo do romance, A morte e o meteoro, é uma narrativa de ficção distópica, pois nos aponta um final 
"calamitoso" e não apenas crítico conforme afirma Perrone-Moisés (2016) ao expor questões acerca da narrativa distópica. Segundo falas do próprio escritor, Joca Reiners Terron, a obra conta a história de uma fictícia tribo indígena brasileira, os kaajapukugi, a qual estava em vias de extinção em função da destruição da floresta onde viviam. Minucioso em suas descrições, Terron, utiliza do espaço para estabelecer uma interação entre os personagens e suscitar a imaginação do leitor. Nesta pesquisa, tentaremos responder o seguinte questionamento: como a perda da espacialidade interfere no enredo da obra A morte e o meteoro?

Desde início dos tempos, o espaço indicava poder e sobrevivência para a espécie humana, aqueles que possuíssem melhor abrigo, conseguiria sobreviver por um período de tempo maior, como bem define Barbosa (2017, p. 52) quando diz que: "as relações de poder ligadas ao espaço sempre se transformam, mas nunca deixarão de existir". Entretanto, o papel desempenhado pelo espaço nem sempre foi unanimidade entre os críticos literários. Para muitos a descrição do espaço não passava de um recorte, sem necessidade, para desviar a atenção do leitor, assim como para inserir uma passagem crítica a fim de fomentar a criatividade do mesmo, antecipar algum momento da narrativa ou verticalizar alguma informação com o intuito de complementar dados antes mencionados. Philippe Hamon (1976, p. 57) diz que a descrição do espaço é "[...] um 'corte' na narrativa, a narrativa 'interrompe-se', o cenário 'passa para primeiro plano', [...]”. Sob a ótica de Hamon, a descrição do espaço seria apenas um hiato na fluidez da narrativa, sem grande influência em sua formação e de pouca relevância no contexto geral de uma obra ficcional.

De outra forma, para Osman Lins (1976), tudo na obra ficcional nos remete a existência de um espaço:

Excetuando-se os casos, hoje pouco habituais, de intromissão do narrador impessoal mediante o discurso abstrato, tudo na ficção sugere a existência do espaço - e mesmo a reflexão, oriunda de uma presença sem nome, evoca o espaço onde a proferem e exige um mundo no qual cobra sentido (LINS, 1976, p. 69).

Em sua obra Espaço e Romance (1985), Antônio Dimas complementa essa importância do espaço, afirmando que em muitas obras narrativas, pode ser prioritário e de fundamental importância no desenvolvimento do enredo, chegando, muitas vezes, ser determinante.

De acordo com Dimas:

Entre as várias armadilhas virtuais de um texto o espaço pode alcançar estatuto tão importante quando outros componentes da narrativa, tais como foco narrativo, personagem, tempo, estrutura etc. É bem verdade que, reconheçamos logo, em certas narrações esse componente pode estar severamente diluído e por esse motivo, sua importância torna-se secundária. Em outras, ao contrário, ele poderá ser prioritário e fundamental no desenvolvimento da ação, quando não determinante. Uma terceira hipótese ainda, está bem mais fascinante!, é a de ir-se descobrindolhe a funcionalidade e organicidade gradativamente, uma vez que o escritor soube dissimulá-lo tão bem a ponto de harmonizar-se com os demais elementos narrativos, não lhe cedendo, portanto, nenhuma prioridade. (DIMAS,1985, p. 5-6)

O fascínio de Dimas (1985) pelo que se pode chamar de aspecto do espaço é resultante do entrelaçamento das microestruturas textuais, proposta desta análise por meio das ideias de Forster (2004). 0 espaço, assim, é um componente funcional que ajuda na análise e na interpretação de um texto, apresentando o mesmo grau de im- 
portância de todos os outros componentes estruturantes da narrativa, o que exemplifica a interdependência das microestruturas narrativas.

Segundo Bachelard:

É pelo espaço, é no espaço que encontramos os belos fosseis de duração concretizados por longas permanências. 0 inconsciente permanece nos locais. As lembranças são imóveis, tanto mais sólidas quanto mais bem especializadas. Mais urgente que a determinação das datas é, para o conhecimento da intimidade, a localização nos espaços da nossa intimidade (BACHELARD, 2008, p.29).

É no espaço que se dará toda a realização das ações das personagens em $A$ morte $e o$ meteoro (2019), em alguma medida a tribo indígena representada no texto só poderia sobreviver no "seu espaço", como na narrativa este espaço já não existe mais, a tribo também não poder mais existir. Há uma íntima relação entre a categoria do espaço e a estruturação do romance, é a partir desta categoria que o desenrolar da história se dá, o motivo para o exílio da tribo é a parda de sua floresta. Em relação ao espaço Cardoso (2011, p. 40), aponta: "é também aspecto intrínseco do texto narrativo, visto que nele se situam os eventos e os personagens". Uma das grandes funções do espaço é a de estabelecer as relações entre as personagens, é nele que tudo se passa no romance

Convém, ainda, destacar a diferenciação feita por Osman Lins entre espaço e ambientação, o qual conceitua ambientação como os modos utilizados para narrar e a construção do ambiente, que se relaciona com o desenrolar da narrativa. E que por ambientação entenderíamos:

o conjunto de processos conhecidos ou possíveis, destinados a provocar, na narrativa, a noção de um determinado ambiente. Para a aferição do espaço, levamos a nossa experiência do mundo; para ajuizar sobre a ambientação, onde transparecem os recursos expressivos do autor, impõe-se um certo conhecimento da arte narrativa (LINS, 1976, p. 77).

Ao contrário dos aspectos denotativos que o espaço nos traz a ambientação destaca seus níveis conotativos, exigindo, dessa forma, capacidade interpretativa do leitor. A ambientação aponta época; aspectos socioeconômicos, psicológicos, características físicas, morais, religiosos, etc. Estabelecida as diferenças entre espaço e ambientação, restam-nos inserir a obra de Terron no contexto da contemporaneidade, antes de enfrentarmos a questão proposta por esta pesquisa que é a perda da espacialidade influenciando o enredo da obra. A morte $e$ o meteoro é uma obra contemporânea, segundo definição de Agamben (2009, p.72), pois nos aponta uma "necessidade que não provém de maneira nenhuma do seu arbítrio, mas uma exigência à qual ele não pode responder".

Em uma busca por resposta do que é ser contemporâneo Giorgio Agamben (2009), indica uma diversidade de significados do que é ser contemporâneo, e conclui que o contemporâneo não é:

apenas aquele que, percebendo o escuro do presente, nele apreende a resoluta luz; é também aquele que, dividindo e interpolando o tempo, está à altura de transformá-lo e de colocá-lo em relação com os outros tempos, de nele ler de modo inédito a história) de "citá-la" segundo uma necessidade que não provém de maneira nenhuma do seu arbítrio, mas de uma exigência à qual ele não pode responder. É como se aquela invisível luz, que é o escuro do presente, projetasse a sua sombra sobre o passado, e este, tocado por esse facho de sombra, adquirisse a capacidade de responder às trevas do agora (AGAMBEN, 2009, p. 72).

A morte e o meteoro trata-se de uma narrativa em que os fatos são relatados por um 
funcionário da Comissão Nacional para o Desenvolvimento dos Povos Indígenas do México e por Boaventura, que no enredo é apresentado como um dos últimos indigenistas ${ }^{1}$ brasileiros. 0 narrador inicial, cujo nome não é apontado no decorrer da trama, é designado para acertar os detalhes e receber a tribo kaajapukugi, a qual pede asilo político ao governo mexicano sob a mediação de Boaventura.

Escrita em quatro capítulos intitulados: Grande Mal; Apagar o sobrenome; Não morrer mais e Cosmogonia, a obra, narrada em primeira pessoa, conta uma história, que se passa em um futuro não muito distante do atual, sobre uma Amazônia completamente destruída. Boaventura, um sertanista com mais de oitenta anos, busca asilo político para os últimos cinquenta homens kaajapukugi remanescentes de uma tribo brasileira, que habitava a região do Alto Purus, completamente em extinção. "Foi o primeiro caso da história das colonizações no qual um povo ameríndio inteiro, os cinquenta kaajapukugi remanescentes, pediu asilo político em outro país" (Terron, 2019, p. 13).

No primeiro capitulo de $A$ morte e o meteoro o narrador lança luz do que seria o epílogo do enredo kaajapukugi:

Hoje vejo o acontecido como o epílogo irrevogável da psicose colonial nas Américas, que eu preferia ter sido apenas mais uma mentira ditada pelos vitoriosos e não a verdade choramingada por outra derrota, agora sem dúvida definitiva (TERRON, 2019, p. 11).

A narrativa de Terron é uma viagem envolvendo vários cenários que se interligam e que relata o contato protagonizado por Boaventura e uma tribo indígena na bacia do rio Purus, na Amazônia. No decorrer da

1 Indigenista ou indianista é um pesquisador(a) especializado(a) no estudo dos povos indígenas. história o autor suscita a imaginação do leitor ao estabelecer verossimilhança entre a ficção kaajapukugi e a realidade do extermínio dos povos indígenas brasileiro. É um cenário em que as cidades se expandem, empurrando agricultura, que expulsa o madeireiro, que fomenta o grileiro, que empurra e extermina o habitat natural do índio.

0 genocídio dos kaajapukugi havia sido deflagrado no final do século XIX, após o êxito tão improvável de sobreviverem a quatro séculos da presença do homem branco no continente, que os obrigava a seguir penetrando, a cada ano, a cada mês, dia e hora, mais e mais léguas de selva, em fuga permanente da perseguição fatal das epidemias de sarampo e gripe trazidas pelos invasores. Após se aproximarem de seringueiros a fim de obter ferramentas metálicas - picaretas, enxadas e facões a serem usados nas suas plantações de mandioca e batata-doce, objetos dos quais se tornaram dependentes a partir do instante em que os descobriram -, doenças dizimaram a maior parte do grupo (TERRON, 2019, p. 19).

No panorama em que a obra é escrita, percebe-se nitidamente uma estreita relação entre a perda do ambiente físico, social e psicológico dos indígenas. Nela Terron conta a história da tribo amazônica kaajapukugi, que surgiu a partir da união dos remanescentes de duas outras tribos, parcialmente extintas, em que se denominavam imenso felino selvagem e o grande lagarto teju. Tribos essas, que sofrendo as consequências da atuação do homem branco, tem sua maioria submetida ao extermínio ou perda da sua cultura pelos sobreviventes.

[...] os primeiros kaajapukugi, integrantes de um povo ora esquecido, viam a si próprios como um único e imenso felino selvagem. Ao perderem membros do seu grupo para a doença e a guerra, tornaram-se um felino de pernas e garras amputadas, sem orelhas e 
com feridas tão graves que não seriam curadas por nenhuma poção ou unguento. A salvação veio na forma dos outros que encontraram, [...], um povo que se identificava com o grande lagarto teju. (TERRON, 2019, p. 22)

Entreveros entre os dois povos passaram a ser comuns, quase sempre causados pelas diferenças de hábitos e crenças, mas o felino não demorou a notar o poder regenerativo da cauda do lagarto, que se renovou e cresceu. Os membros felinos aderiram às reptilidades do lagarto, por assim dizer, e o grande gato se curou. Desentendimentos cessaram ou se tornaram um modo silencioso de evitar assuntos inacessíveis à compreensão de um gato [...]. Para não brigarem, se calavam, e ao se calarem eram tomados por uma grave melancolia que os obrigava ao afastamento dos demais, a se isolarem na selva. Aquele povo recém-formado passou a enxergar a si próprio como um grande gato selvagem com a astúcia do camaleão. [...] Sendo assim, a estrutura social que os abrigava eliminou níveis hierárquicos e a existência de caciques. Também não tinham pajé pra mediar seus conflitos pessoais. Os atuais kaajapukugi são um povo anárquico, não aceitam nenhum tipo de liderança. (TERRON, 2019, p. 23-24)

A participação de Boaventura, um personagem que inicialmente é apresentado como um modelo a ser seguido em defesa de povos isolados, e que no transcorrer dos capítulos descobre-se ser o principal responsável pela extinção dos kaajapukugi:

Ainda faltavam cinquenta e cinco minutos para o final da gravação, e o Boaventura que tinha iniciado, hesitante e assustado, tinha sido substituído por outro Boaventura, cujo comprometimento ético com um povo nativo isolado não parecia mais tão digno de um antropólogo (TERRON, 2019, p. 62).

Nas confissões relatadas através de um vídeo, encaminhado ao funcionário mexicano, Boaventura confessa seu maior crime, classificado pelo indigenista brasileiro como de "lesa-humanidade", aja vista que raptou e contribuiu para o suicídio da última mulher da tribo:

Contudo, na manhã seguinte, quando ela se introduziu sorrateiramente em minha maloca como de costume, movimentando-se agachada com a cumbuca de comida nas mãos, eu a agarrei com força. E aqui está o terceiro motivo, [...], que talvez seja o primordial, seu único motivo, [...], aqui está a confissão dos meus crimes de lesa-humanidade. [...] naquela manhã eu segurei a índia pelo pescoço com uma gravata até ela apagar. Quando caiu inconsciente, eu a joguei nos ombros e enveredei pela área mais fechada da selva em direção ao rio. [...] Com o avançar dos quilômetros, a neblina sobre o Purus se dissipou, e a claridade ressurgiu, iluminando a jovem índia estirada e imóvel no fundo do barco, toda ensanguentada. [...] Com a pressa da fuga, não notei a barriga incipiente que se formava no púbis prenho da índia. Além de ter interrompido sua gravidez, agora ela sofria uma violenta hemorragia, [...]. Ao liberá-la de seus restos, jogando a gosma sanguinolenta na correnteza do rio, não pude deixar de pensar neles como sendo a substância de um futuro que não viria mais. (TERRON, 2019, p. 73-74-75)

A destruição do espaço indígena, por aqueles que os kaajapukugi se referem como o "Grande Mal", também não encontra resistência por parte do Estado, cujos órgãos de fiscalização brasileiros pareciam estar sistematicamente desmobilizados.

A Funai não passava de um tipo de almoxarifado onde o Estado depositava velhos trastes, o que parecia incluí-lo. De todo modo, exceto pela linha telefônica em funcionamento, uma verdadeira relíquia, era como se o escritório já estivesse fechado há anos (TERRON, 2019, p. 17).

Boaventura, ao iniciar seu trabalho de observação dos kaajapukugi, que a Funai só adotaria como regra muitos anos mais tarde, quando ele já tinha envelhecido, somente depois de povos inteiros serem aniquilados 
por uma mera gripe transmitida pelo organismo cristão e antievolucionista de algum missionário protestante tomado de bons sentimentos, mas também de vírus letais. (TERRON, 2019, p. 20)

Eu sabia que na época essas práticas não passavam de esboços teóricos imbuídos de esperança muito inconsistente, pois o expansionismo militar e extrativista pela Amazônia invadia territórios indígenas, e a política preservacionista que permitiria remarcações de reservas ainda estava longe de se tornar realidade. (TERRON, 2019, p. 43)

Para o narrador que se manifesta por meios das palavras de El Negro, um xamã mazateco, responsável pela recepção dos últimos kaajapukugi em Oaxaca, os nativos não passavam de mortos que andavam em direção a lugar nenhum em decorrência da perda dos traços culturais, que os ligavam aos seus deuses. A destruição completa da floresta amazônica havia provocado à desintegração cultural e social da tribo.

0 ecossistema onde viviam foi inteiramente destruído, [...], e com ele suas plantas medicinais sagradas e até os venenos nos quais embebiam flechas e o timbó que usavam pra pescar. Peixes morreram, rios secaram. Tudo desapareceu, até os besouros dos quais extraíam tinsáanhán. Nada restou além de areia e erosão. No rastro do desaparecimento do tinsáanhán, o mundo superior deles também foi tragado, e com ele seus deuses, suas festas e até os três Céus onde descansariam nos campos e caçariam alegremente besouros e fariam amor com suas mulheres. [...] Os hóspedes que o senhor irá receber, ele disse a El Negro, não passam de mortos que andam em direção a lugar nenhum. (TERRON, 2019, p. 24)

Em A morte e o meteoro, a história cíclica dos kaajapukugi termina com o suicídio coletivo dos últimos cinquenta nativos, em um ritual para consumo da última porção de tinsáanhán. A destruição completa da floresta resultou no extermínio do besouro, do qual se extraía o pó para o tinsáanhán. Elemento que alimentava a espiritualidade da tribo e do qual dependia a existência dos indígenas e permitia a ascensão dos kaajapukugi aos três Céus:

a existência dos índios orbitava o rito de colheita do besouro naquele descampado ao redor da tumba [...] eles viviam melancolicamente seus dias vazios sem mulheres ou crianças, à espera da visita à ilha, cuja frequência era determinada pelo ciclo de reprodução dos besouros. (TERRON, 2019, p. 59)

No transcorrer desse trabalho podemos verificar que a perda da espacialidade, em decorrência da destruição da floresta amazônica, ganha relevância para o extermínio dos kaajapukugi. Todos os cenários idealizados, no decorrer da trama, evidenciam que a sobrevivência da tribo estava diretamente ligada à preservação de seus traços culturais, e que a invasão do espaço físico por outros agentes, desencadeou mecanismos que resultou na destruição da tribo. Destarte, a perda do espaço é um elemento decisivo para a construção do enredo em $A$ morte $e$ o meteoro.

\section{Referências}

AGAMBEN, Giorgio. 0 que é o contemporâneo? e outros ensaios. Tradução Vinícius Nicastro Honesk. Chapecó, Santa Catarina: Argos, 2009.

BACHELARD, Gaston. A poética do espaço. Trad. Antonio de Pádua Danesi. 2 ${ }^{a}$ edição. São Paulo: Martins Fontes, 2008.

BARBOSA, Anna Carolyna. 0 espaço, o humano e o espetáculo na distopia pós-moderna de Jogos Vorazes. 2017 f.103. Dissertaçao de Mestrado em Letras - Faculdade de Letras. Universidade Federal de São João del-Rei, São João del -Rei. Disponível em: <https://www.ufsj.edu.br/ portal2-repositorio/File/mestletras/Dissertac\%CC\%A7a\%CC\%83o\%20Anna.pdf> Acesso em: 10 de agosto de 2020 . 
CARDOSO, João Batista. Teoria e prática de leitura, apreensão e produção de texto, 2001.

DIMAS, Antonio. Espaço e romance. São Paulo: Ática, 1987.

GANCHO, Cândida Vilares. Como analisar narrativas. São Paulo: Ática, 2004.

HAMON, Philippe; SALLENAVE, Daniele. Categorias da narrativa. Lisboa: Vega, 1976, p. 57-76.

LINS, Osman. Lima Barreto e o Espaço roma- nesco. São Paulo: Ed. Ática, 1978.

TERRON, Joca Reiners. A morte e o meteoro. São Paulo: Todavia, 2019.

PERRONE-MOISÉS, Leyla. Mutações da literatura no século XXI. São. Paulo: Companhia das Letras, 2016.
Recebido em: 19/08/2021

Aprovado em: 10/10/2021

(c) (i) Esta obra está licenciada com uma Licença Creative Commons Atribuição 4.0 Internacional. 